\title{
DIGITAL MSME DEVELOPMENT IN INDONESIA DURING THE COVID-19 PANDEMIC
}

\author{
Primadona \\ Politeknik Negeri Padang \\ Email:pdmamarafif@gmail.com
}

\begin{abstract}
This article will discuss the growth of Micro, Small, and Medium-Sized Enterprises (MSMEs) during the Covid-19 epidemic. The Covid-19 pandemic has brought the majority of economic sectors, particularly MSMEs, to a standstill. The surplus is that the majority of MSME actors are unable to develop, resulting in widespread bankruptcy. This forces MSME business actors to rethink their sales strategies in light of digitization initiatives. The digitization strategy makes use of an intermediary (marketplace) and social media as a marketing tool. Additionally, actors in the digital MSME sector must collaborate with netizens to sell their products and services. Thus, the digital MSME development strategy may serve as a viable option to business players being rescued during the Covid-19 pandemic. This essay employs a literature review approach, expanding on existing material on the emergence of digital SMEs. This paper contends that as a result of the Covid-19 pandemic, the development of digital MSMEs has become a viable alternative to saving and promoting digital business in Indonesia.
\end{abstract}

Keywords: Covid-19 Pandemic, Digital MSMEs, Netizen.

\section{A. INTRODUCTION}

The global COVID-19 pandemic, which has spread around the world, has impacted every aspect of people's life. In Indonesia, practically every sector is involved, most notably the economic ecosystem, which has been the focus of society. Additionally, the Covid-19 outbreak has slowed the financial industry in Indonesia, which relies heavily on derivatives (Hynes et al., 2020). The Micro, Small, and Medium-Sized Enterprises (MSME) sector, which is a critical component of the economy, has been impacted. All stakeholders are concerned about this since it has resulted in a huge setback for the MSME sector (Revell et al., 2010).

Additionally, numerous MSMEs are currently facing a variety of challenges, including diminishing sales, capital, restricted distribution, trouble obtaining raw materials, dropping output, and numerous layoffs of workers and workers, all of which pose a threat to the national economy (Widiyanto \& Nashrullah, 2020). When it comes to small and medium-sized businesses, productivity is declining, and this is having a direct impact on earnings. Although a survey by the Asian Development Bank (ADB) on the impact of the pandemic on Indonesia's MSMEs found that $88 \%$ of small businesses had exhausted their cash or savings, and more than $60 \%$ had reduced the number of employees they employed as a result (Suhaili \& Sugiharsono, 2019).

The public's reduced outdoor interactions in an effort to slow the spread of the Covid19 pandemic have lowered people's purchasing power, which must be acknowledged. Thus, many customers choose to shop from afar and only use their credit cards for online transactions. As a result of decreased purchases, many MSMEs are forced to close their doors and remain reliant on offline sales. As a result, numerous MSME industries that have not changed digitally 
have been severely impacted and have had to close their doors (Uur \& Akbyk, 2020). Despite this, the Covid-19 pandemic has had an indirect impact on Indonesia's broader economic landscape. Digital entrepreneurship is a term used to describe the transition from traditional company models to online ones. MSME players can benefit from the concept of allowing access to more comprehensive marketing through social media and marketplaces (intermediaries) (Priyono et al., 2020).

It is worth noting that MSMEs have developed into a critical component of Indonesia's economic ecology. As a result, the MSME sector is home to the vast majority of Indonesia's corporate actors. MSMEs accounted for $60 \%$ of the GDP and $97 \%$ of the reemployment of pandemic-affected workers. In the meantime, only $16 \%$ of current MSMEs have entered the digital economy's ecosystem (Chairunnisa et al., 2020). The Indonesian economy relies heavily on micro, small, and medium-sized enterprises (MSME). The MSME sector did play an important part in recovering Indonesia's economic ecosystem during the 1998 financial crisis. Furthermore, the MSME sector proved to be a powerful force for economic recovery during the Covid-19 pandemic (Syapsan, 2019).

As a result, an entrepreneurial model that is adaptable to technology advancements is required. This is how the model of digital entrepreneurship was born. This business model is the result of a marriage of digital technology with entrepreneurship, resulting in a new type of business phenomena. In this instance, the role of digital technology has a major impact on the newly developed business divisions (Ghezzi \& Cavallo, 2020). Emerging technological paradigms enable entrepreneurs to build and launch more robust and durable entrepreneurial ventures by using the potential for cooperation and collective intelligence. Nonetheless, digital entrepreneurship has four dimensions: digital actors (who), digital actions (what), digital motivation (why), and digital organizations (how) (Lyons, 2018).

MSME companies are already connected to digital networks, according to the Ministry of Cooperatives and SMEs. As a result, around 10.25 percent of MSME actors have already established a presence in the digital ecosystem. This is owing to the Ministry of SMEs and Cooperatives' constant implementation of several MSME digitization programs (Obiso et al., 2019). The Ministry of MSMEs and Cooperatives' transformation strategy has a major component: the digitization program. Additionally, as a result of the global epidemic, people's purchasing patterns have shifted. The excessive tendency of digitizing MSMEs has developed into a new habit for the community (Maiti \& Kayal, 2017).

The Covid 19 outbreak in Indonesia has led to an increase in the usage of digital platforms by micro and small enterprises (MSMEs). On Facebook alone, 42\% of Indonesian MSMEs are currently using it to market their businesses! Entrepreneurship and the long-term viability of MSMEs can be fostered by using social media, which is a tool for this purpose. Online sales have grown $26 \%$ to 3.1 million transactions each day, according to McKinsey's analysis (Walsh, 2019). Social media usage surged during the Covid-19 pandemic, which has been connected to an increase in MSMEs' revenue. Digital platforms and social media have played a key role in the success of small and medium-sized enterprises (SMEs) in the current pandemic (Affandi et al., 2020).

Additionally, as MSMEs digitalize, Indonesia's digital economy will become the largest in Southeast Asia by 2025. MSMEs encounter three impediments: To begin, MSME actors continue to be bound by the manufacturing capacity of items. Because of their inability to meet 
the needs of the digital market, many small and medium-sized enterprises (SMEs) fail. MSME actors' resilience isn't fairly distributed in terms of quality, either. Because players must compete in this digital market against major corporations that have also shifted to digital channels (Fauzi \& Sheng, 2020). Thirdly, it is vital to increase the education and human resources of MSME business actors in terms of digital literacy. MSME players are unable to produce their superior products due to a lack of digital literacy and the quality of human resources accessible to them. The majority of small and medium-sized firms (SMEs) are eager to take advantage of the opportunities offered by digital business (Haris et al., 2020).

Diverse aspects such as product quality, production capacity, and digital literacy must be considered while creating digital MSMEs. In order to secure the long-term viability of companies founded in the digital domain, MSMEs must take these three elements into account. Additionally, collaboration with netizens, the millennial generation, is required to build digital SMEs. Through reseller approaches, these citizens can be encouraged to establish digital MSMEs (Mukherjee, 2018). Citizens who can be invited to collaborate, particularly millennials and Generation Z, fall into three categories: buzzers, movers and shakers, and the like. For the digital MSME program's success, government support, notably the ease of licensing, is critical. Connectivity would be improved, which is essential for digital MSMEs (Vitelar, 2019).

The development of digital MSMEs aligns with the Ministry of Communication and Information's (Kominfo) recent establishment of the digital MSME Training Program. This is unreasonable, considering the numerous programs geared to assist MSME actors in making the move to digital platforms for conducting business. It is estimated that by 2021, out of the 60 million MSMEs currently operating in the United States, approximately 30 million will be able to access the digital ecosystem (Lestari et al., 2019). Only 11 to 12 million MSMEs currently sell their products digitally, indicating that a considerable number of companies need to be pushed to use digital media to market their products. Despite this, internet users in Indonesia increased to $73 \%$ in 2020 , yet the digital divide remains relatively considerable. The government must address this by committing resources to the MSME digitalization program. For the development of MSMEs and the support of other programs such as the Job Creation Law, it is essential to improve digital infrastructure. Future consumers may be encouraged to buy more locally made items due to the need of establishing digital infrastructure to support Indonesia's Proudly Made in Indonesia National Movement Program (Dai, 2020).

According to Minister of Cooperatives and Small and Medium-Sized Enterprises (Menkop UKM) Teten Masduki, Indonesia's digital economy has the potential to reach IDR 1,800 trillion by 2025 . As a result, it is critical for MSME players to instantly embrace digital in the development of their business units. This way, foreign items are not able to capture the large market potential. Since there are three elements that MSME companies need to consider when entering the digital realm: quality, capacity, and digital literacy. Consequently (Shambaugh, 2018). MSME actors must emphasise these three points if digital business units are to complement one other and be expected to persist for an extended period of time. In order to keep small and medium-sized enterprises competitive and improve their performance, a digital development strategy for SMEs is needed to supply information technology infrastructure, manufacturing processes and market expansion in the short, medium and long term (Rosca et al., 2018). 
As a result of the current rise of digital platforms such as e-commerce, ride-hailing, and digital payments, Indonesia has the most significant and fastest developing digital economy in ASEAN. MSME actors must take advantage of this potential in order to advance their companies internationally. Furthermore, it is predicted that Indonesia's digital economy will be worth more than US $\$ 130$ billion by 2025 . We must seize this great opportunity to reduce the digital divide between regions, especially for micro-enterprises in a wide range of industries, by emphasizing and extending digital market access.

Additionally, the development of MSME digitalization is not solely focused on digital marketing. However, it is also embracing digital payments in the financial sector. Thus, this move enables MSME actors to settle debts online, which has long been a barrier. Thus, this action will contribute to the proliferation of high-quality MSMEs in Indonesia. Consequently, the development of digital SMEs in Indonesia is likely to result in an increase in the number of Indonesian SMEs that are digitally-based and can thrive in the digital market for a long time. To resurrect this scenario, mitigation and recovery measures must be implemented, including stimulating demand and encouraging digital platforms to grow their collaborations. Additionally, collaboration is essential to use innovation and technology in order to increase product quality and competitiveness during product processing, product processing, and marketing.

Through the various explanations above, the researchers then intend to examine how the development of MSMEs with digital characteristics during the Covid-19 pandemic period.

\section{B. LITERATURE REVIEW}

It is possible to save the MSME sector by developing digital-based MSMEs during the Covid-19 pandemic. Digital transformation has been stressed in recent months by the Ministry of Cooperatives and Small and Medium-Sized Enterprises, as well as by the government itself. Thus, the Covid-19 epidemic has aided in the growth of the digital entrepreneurship environment. In this context, digital entrepreneurship refers to a type of business that makes use of the sophistication of digital technology, both in terms of procedures and goods. All businesses who sell their products online, whether through a website or an app, are considered to be digital entrepreneurs. Technology and social media are used in digital marketing for ecommerce. Because of this, it is possible that the future of digital entrepreneurship could play a key role in Indonesia's economic development. This can be attributed to the growing importance of information technology in business. The character and nature of a more digitallybased entrepreneurial model have been altered by digital technology.

Additionally, social media is increasingly creating new business prospects for the community to establish digital entrepreneurship models in an economic environment. When examined closely, the term "digital entrepreneurship" originates from the term "technopreneur," which translates as "digital entrepreneur" and is derived from the words "technology" and "entrepreneur." In general, the term "technology" refers to the practical application of science to the operation of industry, such as tool development, skill development, and issue solving. At the same time, the term "entrepreneur" refers to an individual or group of individuals who do business with the guts to accept risks and uncertainties in order to profit from current chances (Kenner \& Zysman, 2016). This identification demonstrates that the digital entrepreneurship phenomenon would create numerous public opportunities for 
entrepreneurs, particularly at the small and medium-sized enterprise (SME) level. This can be attributed to the fact that the digital entrepreneurship model provides a plethora of convenient and comfortable solutions at cheaper prices and rates. For this reason, it is not enough to simply know how to do one or two things well in the technological field to be considered a successful digital entrepreneur. Hence, a wide range of stakeholders, such as digital entrepreneurs, research institutions, capital providers and governments, must be involved in business development in the technology industry (Allahar \& Brathwaite, 2016).

According to Chayapa \& Cheng Lu's study, various factors influence a person's decision to shop online, including the following:

a. Convenience. This feature is critical because the majority of people begin avoiding crowds and jostling when shopping in shopping centers. Thus, shopping online becomes a new option that can help make it more efficient.

b. Exhaustive data. The existence of information technology enables quick and easy access to information. Additionally, there are a number of platforms that offer various information, rating, and review options for users to give input on the quality and expertise of the content.

c. Product and service availability. Individuals can immediately determine the availability of goods without visiting the store by accessing the website. This can also benefit potential purchasers who are unable to visit the store but wish to purchase things online.

d. Cost and time savings. Certain websites frequently offer potential consumers the best discounts by evaluating pricing across multiple stores simultaneously. For prospective purchasers, this pricing comparison becomes relevant. Additionally, internet shopping can be conducted from any location (Nwokah \& Ntah, 2017).

In other words, the digital entrepreneurship model will foster innovation in order to establish a new ecosystem for MSMEs capable of increasing the country's production and welfare. Additionally, with this strategy, MSME actors will continue to be driven to advertise their products through the use of network technologies. The surplus of MSMEs will swiftly adapt to the digital environment and compete on a global scale.

\section{METHOD}

This research will be carried out using a qualitative approach as the main method. The research data used were obtained from various literature studies or the results of previous studies that are still related and relevant to this research. The data that has been collected will then be analyzed, so that in the end, the expected conclusions can be found.

\section{RESULT AND DISCUSSION}

\section{Digital Economy Ecosystem}

The issues confronting MSMEs in Indonesia are quite complex, as they are inextricably linked to the country's low entrepreneurship rate of 3.5 percent. As a result, boosting the quality of MSMEs is critical for future conditions of ease of doing business. It is worth noting that MSMEs have been critical in consolidating the Indonesian economy. MSMEs have developed into one of the main pillars and supporters of the Indonesian economy, based on experience during the country's economic crises. However, during the Covid-19 pandemic, the MSME sector stayed mostly unchanged, and it now need a strategy for digital transformation in order 
to survive. Only 45 percent of MSMEs survived for three months during the Covid-19 pandemic, according to BPS data as of September 2020, while the rest perished.

Thus, one strategy adopted by Japan's government to encourage the development of digital MSMEs is to recruit young innovators to help with the MSME Digital Hero program. In order to help MSME players withstand the Covid-19 pandemic, this campaign utilizes the digital ecosystem to increase sales. In light of the fact that only around 10-11 million MSMEs have access to the digital economy.

There is a four-step approach to developing SME digitization by the Kemenkop UKM, as well: MSME firm owners can be trained in order to increase their competencies and human resources. Due to the fact that human capital is essential for the growth of MSMEs in the digital age. Due to a lack of understanding, many MSME actors admit that they confront several obstacles to digitalization and social media use. Simultaneously, MSME actors must possess a high level of knowledge in the usage of marketplaces, social media, and mobile applications. MSME players can also use the Drone Emprit Academic application to evaluate public sentiment on trending social media platforms.

The second objective is to intervene in order to improve MSME business operations, which are subsequently converted into a variety of programs. Along with marketing methods, MSME actors must understand the value of financial literacy. Because financial literacy would enable MSME players to manage their business units in a systematic manner, particularly when it comes to debt and receivables management. This financial literacy also includes the methods for accounting for MSME's. Due to implementation challenges, the majority of MSME actors in Indonesia have not registered to apply the Financial Accounting Standards for Entities Without Public Accountability (SAK ETAP). These impediments are a result of the low quality of MSME financial reports.

It is also hoped that through working with the Government Goods/Services Procurement Policy Institute (LKPP), the Ministry of Cooperatives and SMEs will be able to become vendors of goods and services purchased by the government. Fourthly, to extol the virtues of SMEs' local heroes. Micro and small businesses need a local hero who can help them get started, enable them to create a brand, and bring them together to sell on digital platforms or in international markets (exports). It will be necessary to reestablish this position by increasing demand and encouraging digital platforms to build their contacts throughout the Covid-19 outbreak, as well as mitigation and recovery efforts. Product quality and competitiveness can only be improved by collaboration between product processing, processing, and marketing departments, as well as innovation and technology.

There are a number of ways created by the Ministry of Cooperative and Small and Medium-Sized Enterprises to help MSMEs digitize during the current Covid-19 pandemic. It's time for stakeholders, like businesses and institutions, to work together with MSMEs in order to speed up digital transformation. Millennials will be more inclined to start their own businesses if the digital transformation of MSMEs is accelerated. This would eventually result in the emergence of young innovators who will launch a variety of startup businesses addressing MSME concerns in the Indonesian environment. MSMEs' digital transformation will be accelerated by the existence of MSME-based startups. This will bolster Indonesia's institutionalization of the digital economy. 


\section{The Urgency of Creative Content}

The development of digital-based SMEs in Indonesia must consider a variety of factors, not the least of which is creative content. Because in the digital world, content is the primary pillar upon which businesses compete. Without unique content, it is undoubtedly difficult for digital-based SMEs to achieve meaningful outcomes. In this environment, MSME players must explore new content design both autonomously and through varied extra training. The digital world's characteristics, especially social media, must be taught to MSME actors. Consumers are more likely to pay attention to products and services if they are advertised in a way that is interesting to them. When it comes to digital marketing, creative content is essential for small and medium-sized enterprises. According to a slew of research, unique material can pique the interest of netizens. If this information comes from the MSMEs' own products and services, it is virtually definitely content that supports the MSMEs' offerings.

MSMEs in Indonesia face a number of challenges, including difficulties in promoting their products and services. These roadblocks include everything from product management (packing and branding) to marketing strategies. Because of the Covid-19 epidemic, MSME actors must adapt to the digital age, especially in terms of digital marketing. In terms of bottlenecks, packaging is the most significant. Because there are still a large number of MSME products and services available in Indonesia that are being marketed as original completed goods. As a result, the items and services offered lack an enticing value that would capture the attention of consumers. In order to get the attention of customers, a wide range of assistance is needed in the form of instruction on how to package products and services attractively. To put it another way, product packaging and branding require innovative methods to content production. If the product is advertised on social media and in markets, it is certain to draw the attention of potential buyers. Finally, if products and services are well-packaged, digital marketing will be deemed a success.

The second obstacle for MSMEs is their low marketing costs, or the cost of advertising their products and services. Marketing benefits of social media must be utilized by MSMEs in this case. This means that MSMEs would be able to advertise their items digitally if they are able to bundle creative material. With this digital marketing strategy, it is important to know about and use apps like EUMKM that may help with marketing, such as selling MSME things as a possible step toward strengthening the Indonesian economy

As a result, MSMEs must consider various factors when developing innovative content. MSME performers must develop skills in photography, videography, and innovative sentence construction for social media. These three requirements must be met by MSME actors in order for the public to learn about their products and services. To begin, let us discuss photographic approaches. In this instance, each MSME actor must take beautiful and high-resolution photographs of their products and services. When products and services are shared on social media, learning effective photography techniques results in visually appealing products and services. As a result, a third party must continue to provide extensive training to MSME actors in order for them to produce stunning product photographs.

The second is the method of videography. MSME actors must also develop video material, as creative video content ranks higher in search results than image or photo content. According to a number of research, videos are expected to gain more traction. Last but not least, the sentences should be as intriguing as they can be. An effective social media post is all 
about the caption. As a result, MSME actors must acquire the ability to write effectively in order to make the phrase structure more appealing.

The development of digital MSMEs necessitates a wide range of training, from branding and package design to photojournalism, creative videography, and creative writing. MSME participants must also receive digital marketing training on all currently available social media channels (digital marketing). With the use of digital media and direct sales, MSMEs are hoping to increase their sales and competitiveness.

\section{Building Synergy Between Digital MSMEs and Netizen}

When it comes to social media and the digital age, the online community's role is intrinsically intertwined. In order for a product or service to be successful, it needs to be noticed by the public. In this example, the netizen's identification on social media. There are various classifications in a digital society or Netizen. Netizens are active users of a variety of social media platforms who engage in digital interactions in cyberspace.

Additionally, netizens are classified according to their level of involvement on social media. The phrase is derived from many terms referring to the process of amplifying and spreading digital communications or material. In a digital world, buzzers, influencers, and followers all play important roles. A buzzer is a social media account that acts at any time to promote, campaign, and broadcast messages or digital information to other citizens in an effort to influence or reinforce the message. Influencers, on the other hand, are social media users who have a substantial impact on their audience. Influence and persuasion can be achieved through the use of these accounts. Social media accounts that emulate the actions of influencers and buzzers are known as followers. The followers of influencers and buzzers are citizens who are obedient to the authority of the people they are following. When developing social media marketing strategies for MSME enterprises, these three netizen players must also be taken into account.

Additionally, in order to develop digital-based MSMEs, MSME players must collaborate with netizens through the exhibition of creative content. By delivering original material, it may automatically garner the attention of netizens and entice them to help spread the word about their products. As a result of this synergy, the products and services given by MSMEs will become widely known among netizen actors. Additionally, the synergy is generated by the use of reseller strategies. This strategy entails inviting netizens from generation $\mathrm{Z}$ to join in the reselling of MSMEs' products. The millennial generation's reseller strategy will be a fantastic marketing channel. This is due to the fact that the millennial age has a diverse network of friendship nodes. It is hoped that this synergy will result in a growth in the promotion of digital MSME products. Additionally, this reseller strategy must incorporate Lazada, Tokopedia, Shopee, and other marketplaces. Thus, marketing media will create opportunities for MSME items to become widely recognized to netizens via this marketplace.

The final strategy is to engage netizens, particularly Generation Z, in promoting MSME products and services. This strategy enables millennial netizens to provide endorsements for MSME items using their personal social media platforms. With this testimonial strategy, which is subsequently propagated over all of the individual residents' social media platforms, it can serve as at least one promotional medium. More netizens who offer testimonies show that Indonesian customers will accept digital MSMEs' products more likely. MSME company 
players will have a difficult time promoting their items on social media if they don't collaborate with the public. Thus, expertise ranging from getting to know netizen players to viral strategies must be mastered by digital MSME actors in order to compete. This type of information must be acquired by MSME players through support and other forms of training provided by third parties or on their own.

\section{E. CONCLUSION}

The Covid-19 pandemic has stifled Micro, Small, and Medium-Sized Enterprises (UMKM), to the point where some have been forced to close their doors. This is due to the development of new habits associated with the application of health protocols, which has a negative effect on people's purchasing power. Within the framework of Indonesia's economy, the Covid-19 epidemic has the potential to finally spur the development of a new ecosystem, notably digital entrepreneurship. In other words, this ecosystem has prompted MSME actors to embark on a digital transformation. Nonetheless, the government has attempted to push a digitization initiative for MSMEs in Indonesia thus far. This may be seen in the way MSME actors have adapted to the usage of market places and social media in digital marketing. Additionally, social media channels have become a primary focus for MSME actors. Additionally, MSME actors have begun to adapt through the use of a variety of enabling apps, such as digital banking platforms. MSMEs may eventually redevelop their enterprises as a result of the Covid-19 pandemic's digital transformation. Thus, developing digital MSMEs amid the Covid-19 pandemic may be a viable approach to rescuing the MSME sector.

\section{REFERENCES}

Affandi, A., Sarwani, A. S., Erlangga, H., Siagian, A. O., Purwanto, A., Effendy, A. A., \& Juhaeri, G. (2020). Optimization of MSMEs empowerment in facing competition in the global market during the COVID-19 pandemic time. Systematic Reviews in Pharmacy, 11(11), 1506-1515.

Allahar, H., \& Brathwaite, C. (2016). Business incubation as an instrument of innovation: the experience of South America and the Caribbean. International Journal of Innovation: IJI Journal, 4(2), 71-85.

Chairunnisa, S. M., Alfina, A., \& Yasmin, A. (2020). Observing Micro, Small, and Medium Enterprises (MSMEs) Readiness to Support Cashless Society. The Winners, 21(2), 101106.

Dai, R. M. (2020). Fintech As A Catalyst For Growth Of Micro, Small And Medium Enterprises In Indonesia. Academy of Strategic Management Journal, 19(5), 1-12.

Fauzi, A. A., \& Sheng, M. L. (2020). The digitalization of micro, small, and medium-sized enterprises (MSMEs): An institutional theory perspective. Journal of Small Business Management, 1-26.

Ghezzi, A., \& Cavallo, A. (2020). Agile business model innovation in digital entrepreneurship: Lean startup approaches. Journal of business research, 110, 519-537.

Haris, M., Iqbal, M., \& Hadiyati, P. (2020). Synergy of Sharia Banks and Financial Technology in The Development of Micro, Small and Medium Businesses in Indonesia. Jurnal Reviu Akuntansi Dan Keuangan, 10(1), 115-126.

Hynes, W., Trump, B., Love, P., \& Linkov, I. (2020). Bouncing forward: a resilience approach to dealing with COVID-19 and future systemic shocks. Environment Systems and Decisions, 40(2), 174-184. 
Kenney, M., \& Zysman, J. (2016). The rise of the platform economy. Issues in science and technology, 32(3), 61.

Lestari, A., Pratama, C., \& Sunardi, S. (2019). Digital Marketing to Advance the Creative Industry. International Journal of Technology Management and Information System, 1(1), 30-38.

Lyons, G. (2018). Getting smart about urban mobility-aligning the paradigms of smart and sustainable. Transportation Research Part A: Policy and Practice, 115, 4-14.

Maiti, M., \& Kayal, P. (2017). Digitization: Its impact on economic development \& trade. Asian Economic and Financial Review, 7(6), 541-549.

Mukherjee, S. (2018). Challenges to Indian micro small scale and medium enterprises in the era of globalization. Journal of Global Entrepreneurship Research, 8(1), 1-19.

Nwokah, N. G., \& Ntah, S. W. (2017). Website quality and online shopping of e-tail stores in Nigeria. Journal of Service Science and Management, 10(06), 497.

Obiso, J. J. A., Himang, C. M., Ocampo, L. A., Bongo, M. F., Caballes, S. A. A., Abellana, D. P. M., ... \& Jr, R. A. (2019). Management of Industry 4.0-reviewing intrinsic and extrinsic adoption drivers and barriers. International Journal of Technology Management, 81(3-4), 210-257.

Priyono, A., Moin, A., \& Putri, V. N. A. O. (2020). Identifying digital transformation paths in the business model of SMEs during the COVID-19 pandemic. Journal of Open Innovation: Technology, Market, and Complexity, 6(4), 104.

Revell, A., Stokes, D., \& Chen, H. (2010). Small businesses and the environment: turning over a new leaf?. Business strategy and the environment, 19(5), 273-288.

Rosca, E., Reedy, J., \& Bendul, J. C. (2018). Does frugal innovation enable sustainable development? A systematic literature review. The European Journal of Development Research, 30(1), 136-157.

Shambaugh, D. (2018). US-China rivalry in Southeast Asia: power shift or competitive coexistence?. International Security, 42(4), 85-127.

Suhaili, M., \& Sugiharsono, S. (2019). Role of MSME in Absorbing Labor and Contribution to GDP. Economics Development Analysis Journal, 8(3), 301-315.

Syapsan, S. (2019). The effect of service quality, innovation towards competitive advantages and sustainable economic growth: Marketing mix strategy as mediating variable. Benchmarking: An International Journal, 26(4), 1336-1356.

Uğur, N. G., \& Akbıyık, A. (2020). Impacts of COVID-19 on global tourism industry: A crossregional comparison. Tourism management perspectives, 36, 100744.

Vițelar, A. (2019). Like me: Generation $Z$ and the use of social media for personal branding. Management Dynamics in the Knowledge Economy, 7(2), 257-268.

Walsh, J. (2019). 11 Internet services and the potential for market access for rural agricultural households in Myanmar and Viet Nam. In Developing the Digital Economy in ASEAN (pp. 232-255). Routledge.

Widiyanto, P., \& Nashrullah, N. (2020). The Role of Transportation and Logistics Infrastructure in Increasing MSMEs in Indonesia (Study in the New Normal Era). Sustainable Competitive Advantage (SCA), 10(1), 558-567. 